Research Article

\title{
The Influence of Different Parameter on the Seismic Behavior of SRUHSC Frame
}

\author{
Yingchao Ma and Jinqing Jia \\ The State Key Laboratory of Coastal and Offshore Engineering, Dalian University of Technology, Dalian, Liaoning 116024, China \\ Correspondence should be addressed to Yingchao Ma; mayingchao1985@163.com
}

Received 22 March 2017; Accepted 24 May 2017; Published 10 July 2017

Academic Editor: Charles C. Sorrell

Copyright (C) 2017 Yingchao Ma and Jinqing Jia. This is an open access article distributed under the Creative Commons Attribution License, which permits unrestricted use, distribution, and reproduction in any medium, provided the original work is properly cited.

\begin{abstract}
The seismic behaviors of steel reinforced ultrahigh strength concrete (SRUHSC) frames with different axial compression ratios and shear span ratios are experimentally studied through the reversed cyclic loading test of four specimens. The test results reveal that the seismic response of the frame is closely related to the failure process and failure mode of the columns. Based on the results, a systematic exploration is further conducted in terms of the characteristics of the skeleton curve, hysteresis curve, strength degradation, stiffness degradation, and energy dissipation capacity of the structure. The results indicate that as the axial compression ratio increases, and the shear span ratio decreases, the failure process of the entire structure and the weakening of the beam end are accelerated. Meanwhile, a change of the failure mode is also observed, accompanied by corresponding changes in the strength, stiffness, and energy dissipation capacity of the system.
\end{abstract}

\section{Introduction}

In order to satisfy the demand of the explosive development of high-rise buildings in modern cities, construction techniques using steel and concrete have been widely used because steel possesses favorable toughness and tensile mechanical properties, while concrete exhibits excellent compression performance and can exhibit an economical advantage in mass production. Furthermore, a composite combines the advantages of the two materials and thus further enhances the lateral force and bending moment resisting capacity of the entire structure [1]. As more and more high-rise buildings are being designed and constructed in these years, the utilization of high and ultrahigh strength concrete becomes more and more necessary. In such cases, a more demanding concrete strength, that is, a selected concrete compressive stress of more than $100 \mathrm{Mpa}$, is required to improve the sectional load bearing capacity of structural components [2-5]. However, some inherent disadvantages of high and ultrahigh concrete exist, such as brittleness. This disadvantage can result in the abrupt failure of the structure under seismic loading without notable lateral deformation and energy dissipation capacity, which is specifically prohibited in the seismic design provisions of many countries, where steel needs to possess sufficient ductility and deformation capacity. Meanwhile, the restraint of the composite stirrups in concrete significantly increased the deformation capacity of concrete. Attard and Setunge [6] suggested that the stressstrain relationship of confined concrete was applicable to a wide range of concrete strength including the common, high, and ultrahigh strength concrete, but only applicable to the structure with symmetrical hoops. Kent and Park [7] raised the stress-strain relationship of concrete in composite square stirrup. According to this model, the stirrup just affected the descending stage of the curve, while it did not significantly affect the ascending part. Although the composite square stirrup did not improve the concrete strength, the deformation ductility of concrete would be dramatically improved. Park et al. [8] further modified this model to consider the effect of stirrup on the stress-strain relationship of concrete peaking. Scott et al. [9] carried out the research of constraint of concrete composite stirrup under different strain rates. Moreover, a composite decreases the brittleness of ultrahigh strength concrete; hence, steel and concrete represent a feasible combination for the construction of high and ultrahigh buildings. 
TABLE 1: Concrete content.

\begin{tabular}{lccccccccc}
\hline \multirow{2}{*}{ Category } & \multirow{2}{*}{ Strength grade } & \multicolumn{9}{c}{ Unit volume quality $/\left(\mathrm{kg} \cdot \mathrm{m}^{-3}\right)$} \\
& & Cement & Fly ash & Silica & Coarse aggregate & Sand & Water reducer & Retarder & Water \\
\hline Column & C100 & 420 & 120 & 60.0 & 1155 & 495 & 9.00 & 0.30 & 138 \\
Beam & C40 & 352 & 88 & 0.00 & 1074 & 716 & 5.94 & 0.00 & 198 \\
\hline
\end{tabular}

TABLE 2: Mechanical properties of concrete.

\begin{tabular}{lccc}
\hline Strength grade & $\begin{array}{c}\text { Cube compressive strength average } \\
f_{\text {cum }} / \mathrm{MPa}\end{array}$ & $\begin{array}{c}\text { Prism compressive strength average } \\
f_{c m} / \mathrm{MPa}\end{array}$ & $\begin{array}{c}\text { Modulus of elasticity } \\
E_{c m} / \mathrm{GPa}\end{array}$ \\
\hline C40 & 47.3 & 41.55 & 33.4 \\
C100 & 113.55 & 105.5 & 47.33 \\
\hline
\end{tabular}

It is widely accepted that columns play a significant role in controlling the seismic behavior of steel reinforced concrete frame structures. However, research on the seismic performance of SRUHSC frame is quite limited at the present, which can be generalized from three aspects. First of all, the specification requirements with regard to this type of structural system have obviously lagged behind compared to its application in practical projects. In the concrete design codes of many countries, such as European nations, the United States, and China [10-13], the concrete strength is almost always limited within the range of C80; thus, a compressive strength value beyond $100 \mathrm{Mpa}$, which is usually defined by ultrahigh strength concrete, is not code-accessible, which consequently impedes the development of this structural system to some extent. Secondly, existing work has mainly focused on ordinary strength concrete at the component level [14-18], while research on the seismic behavior of SRUHSC frame structures still remains at the theoretical stage [19-21]. For the SRUHSC system, the influence of columns on the overall system, as well as the global response of the frame structure, has not been systematically explored. SRUHSC research is of great significance, considering its growing application demands in the near future. Moreover, this type of research also solves detailed problems of engineering applications; thus, experimental investigations of SRUHSC structures are indispensable for obtaining their seismic performances. This paper aims at filling in this gap by systematically analyzing the characteristics of this type of structure, which establishes a deformation model of the entire structure. Moreover, the seismic behaviors of SRUHSC frames are analyzed.

\section{Experimental Overview}

2.1. Design Principle. A one-story, one-bay frame is the basis element of a multiple floor structure, which plays an important role on the seismic behavior of the structure. Thus, a proper design is required. According to the code for the seismic design of buildings [22], the design code of the SRUHSC frame structure has three main requirements, which is described as follows.
First, the flexural carrying capacity ratio of beam to column needs to be greater than 1.2 in order to ensure the formation of strong column-weak beam mechanism and to satisfy the requirement in the seismic design code. Second, the total height of the column is $1500 \mathrm{~mm}$ and the calculated height is $1200 \mathrm{~mm}$, with slenderness ratios of 7.5 and 6 , respectively, in order to meet the requirements of the specification, that is, less than 8 . The main reason is to avoid column lateral buckling in the process of loading. Third, the linear stiffness ratio of beam and column should not be greater than one over 0.45 , which exerts great influence on the lateral deformation capacity and thus the seismic behavior of the SRUHSC frame. The SRUHSC frame is designed to satisfy the code. The specific section type and layout are shown in Figures 1 and 2, and the specific material parameters are shown in Tables 1 and 2.

2.2. Specimen Layout. The specimens are designed by strictly following the three principles as mentioned above. To meet the requirements in the seismic design code, details and construction measurements of the specimens are described as follows. The span of the whole structure is $2000 \mathrm{~mm}$, and the stirrup spacing of the beam and column is equivalent to $60 \mathrm{~mm}$. The composite stirrup spacing of the joint zone is $50 \mathrm{~mm}$, and the thickness of the concrete cover is $20 \mathrm{~mm}$. Furthermore, the rectangular cross sections of beam and column have dimensions of $160 \times 200 \mathrm{~mm}$ and $200 \times$ $200 \mathrm{~mm}$, respectively. A composite stirrup is adopted by the combination of square and polygon. Concrete strength grades of C40 and C100 are utilized as material attributes for the beams and columns, respectively, and the concrete content proportions are shown in Table 1 and the measured values of the concrete compressive strength are shown in Table 2.

Test results indicated that the value of slump fully satisfied the fundamental requirements. A minimum value of $150 \mathrm{~mm}$ for the low side value of pumping is required, and the testing slump of ultrahigh strength concrete is approximately equal to $200 \mathrm{~mm}$. Meanwhile, the isolation phenomenon for aggregate does not appear. Moreover, this result has been verified by hundreds of tests in our research group; thus the behavior of ultrahigh strength concrete is stable and reliable. On the other hand, the condensation rate of 


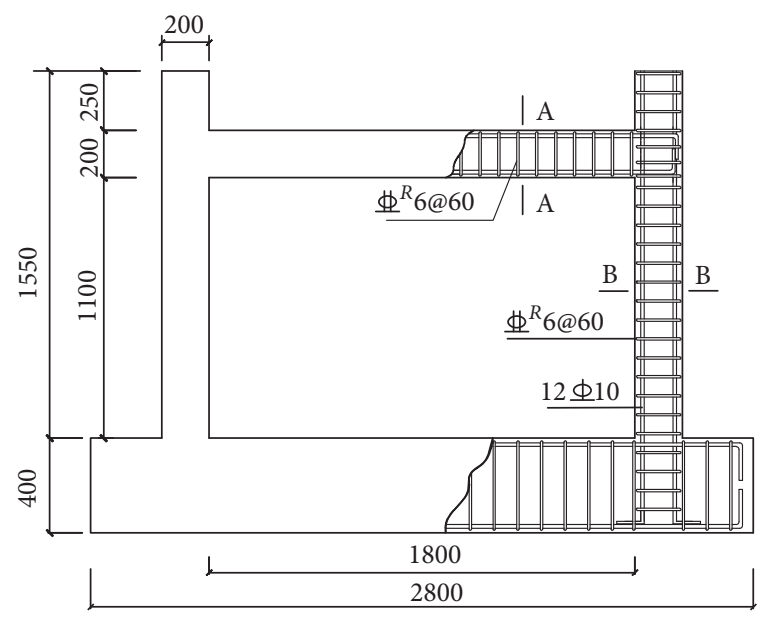

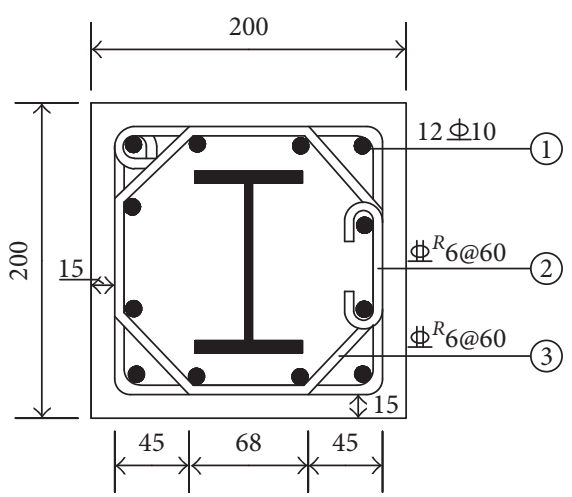

B-B column section

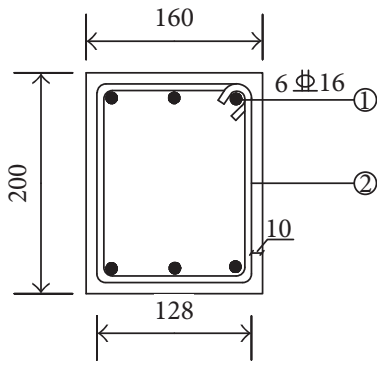

A-A beam section

Ф: HRB235

\$: HRB335

(a) Plane diagram

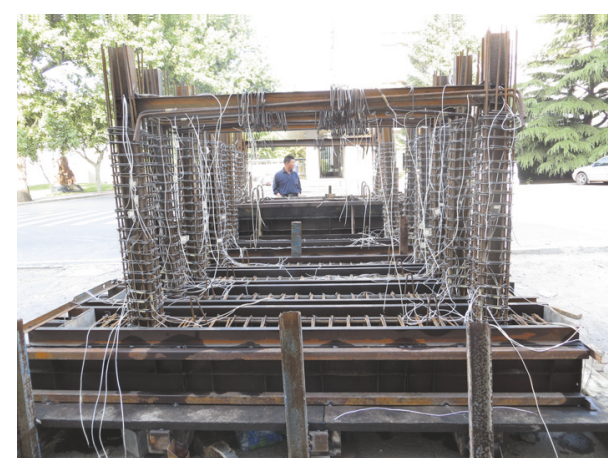

(b) Constructional photo

FiguRE 1: Frame reinforcement diagram.

ultrahigh strength concrete is faster than that of common strength concrete, and the initial setting time is more than 30 minutes, which is less than 45 minutes for common strength concrete. This attribute is specially useful for emergency engineering such as quick construction and road reparation. Although the ultrahigh strength concrete will lose partial workability, its basic workability can satisfy the engineering requirement.

The detailed layout of frame structure is shown in Figure 1(a), the constructional photo is Figure 1(b), including the longitudinal rebar and shape steel layout, style of the stirrup, and detailed construction, and the section construction of the column consists of 12 longitude bars with a diameter of $10 \mathrm{~mm}$, I shape steel, and composite stirrup, and that of the beam section is composed of 6 longitude bars with a diameter of $16 \mathrm{~mm}$ and rectangular stirrup. The thickness of the concrete cover for the column and beam is $15 \mathrm{~mm}$ and $10 \mathrm{~mm}$, respectively, and the simple elevation drawing is shown in
Figure 2, the partial longitude bars are hided to conveniently review the picture, and the material parameters are listed in Table 3.

\section{Test Setup}

The loading principle of the frame test is extremely similar to that of the column test. The test setup is shown in Figure 3. The reaction beam undertakes the column axis force, and the rollers between the reaction beam and jack bottom ensure a constant force in the vertical direction. Two steel rods connected to two ends of the beam are used to transmit the pulling force of the specimen. The steel beam in the floor prevents the specimen from moving to guarantee date accuracy.

In the process of the quasi-static test loading, the experimental axial compression ratios are $0.25,0.38$, and 0.45 , respectively, and shear span ratios are 2 and 3 . The main 
TABLE 3: Steel material properties.

\begin{tabular}{lcccc}
\hline Category & Type & Diameter and section dimension & $\begin{array}{c}\text { Yield strength } \\
f_{y} / \mathrm{MPa}\end{array}$ & $\begin{array}{c}\text { Ultimate strength } \\
f_{y} / \mathrm{MPa}\end{array}$ \\
\hline Steel & $\mathrm{I} 10$ & $100 \times 68 \times 4.5 \times 7.6$ & 254 & 368 \\
Stirrup & $\Phi^{R} 6$ & 6 & 500 & 718 \\
Longitudinal bar & $\Phi 10$ & 10 & 424 & 620 \\
Longitudinal bar & $\Phi 16$ & 16 & 360 & 570 \\
\hline
\end{tabular}

$\Phi$ is HRB235

$\$$ is HRB335

$\Phi^{R}$ is HRB400

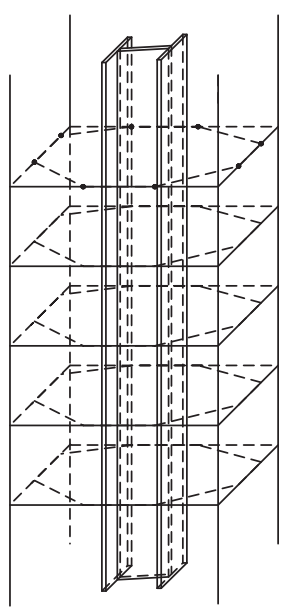

Figure 2: The simple elevation drawing.

reason is that the design axial compressive ratio is approximately twice the experimental axial compressive ratio. They meet the requirements of the code for the seismic design of buildings [23], and the axial compressive ratio is represented as follows:

$$
\begin{gathered}
n=\frac{F}{f_{c m} A_{g}}, \\
n_{d}=\frac{F_{d}}{f_{c d} A_{g}},
\end{gathered}
$$

where $F$ is the axial compression of the column, $F_{d}$ is the design value of the column axial compression, $f_{c m}$ is the average prism compressive strength, $f_{c d}$ is cube compressive strength design value, and $A_{g}$ is the section area of the column.

For ultrahigh strength concrete, the variation coefficient of the concrete compressive strength $\delta$ is equal to 0.008 . The relationship between the design value and experimental value is approximately expressed as

$$
\begin{aligned}
n_{d} & =\frac{F_{d}}{f_{c d} A_{g}} \approx \frac{1.25 F}{\left(f_{c u} / 1.4\right) \cdot A_{g}}=\frac{1.4 \times 1.25 F}{(1-1.645 \delta) \cdot f_{c m} A_{g}} \\
& \approx 2 \times \frac{F}{f_{c m} A_{g}}=2 n .
\end{aligned}
$$

TABle 4: Design parameters of the specimens.

\begin{tabular}{lccc}
\hline $\begin{array}{l}\text { Specimen } \\
\text { number }\end{array}$ & Steel style & $\begin{array}{c}\text { Shear span } \\
\text { ratio }\end{array}$ & $\begin{array}{c}\text { Experimental axial } \\
\text { compression ratio }\end{array}$ \\
\hline $\begin{array}{l}\text { SRUHSC-RC- } \\
\text { N25-I3 }\end{array}$ & I10 & 3 & 0.25 \\
$\begin{array}{l}\text { SRUHSC-RC- } \\
\text { N38-I3 }\end{array}$ & I10 & 3 & 0.38 \\
$\begin{array}{l}\text { SRUHSC-RC- } \\
\text { N45-I3 }\end{array}$ & I10 & 3 & 0.45 \\
$\begin{array}{l}\text { SRUHSC-RC- } \\
\text { N38-I2 }\end{array}$ & I10 & 2 & 0.38 \\
\hline
\end{tabular}

Notes. SRUHSC and RC stand for steel reinforced ultrahigh strength column and reinforced concrete beam, respectively; I2 stands for 10 style steel and shear span ratio of 2 (others are equivalent to a value of 3 ); $\mathrm{N}$ stands for the axial compression ratio.

Thus, the design axial compressive ratios corresponding to the experimental axial compressive ratios are $0.5,0.75$, and 0.9 , respectively. $F / A_{g} f_{c m}=0.25$ represents the axial compressive level of the cross-section balance destruction; 0.38 meets the requirements of the code [24] for seismic grade two with a shear span ratio of greater than 2 . The limit value of the axial compression ratio of steel caused by ordinary strength concrete columns is equal to $0.38 ; 0.45$ is for unpredictable events, which may occur under strong earthquakes.

The purpose of the test is to verify the seismic behavior of the composite frame structure under different conditions. The details of the parameters are shown in Table 4. Displacement control by drift angle is adopted as the loading procedure $[25,26]$. The former of the three amplitudes repeats only once at each displacement level. The amplitude increment is $0.25 \%$, which is also the test amplitude at the beginning. From the beginning of the fourth amplitude, its increment is $0.5 \%$, and details are shown in Figure 4. Each degree repeats three times until the bearing capacity decreases to $80 \%$ of the maximum bearing capacity or until the structures suddenly lose bearing capacity [27, 28], which leads to final failure. In the process of loading, the behavior of the entire frame structure during the loading is monitored by a number of displacement gauges and strain gauges, as well as an electrohydraulic servo control system. 


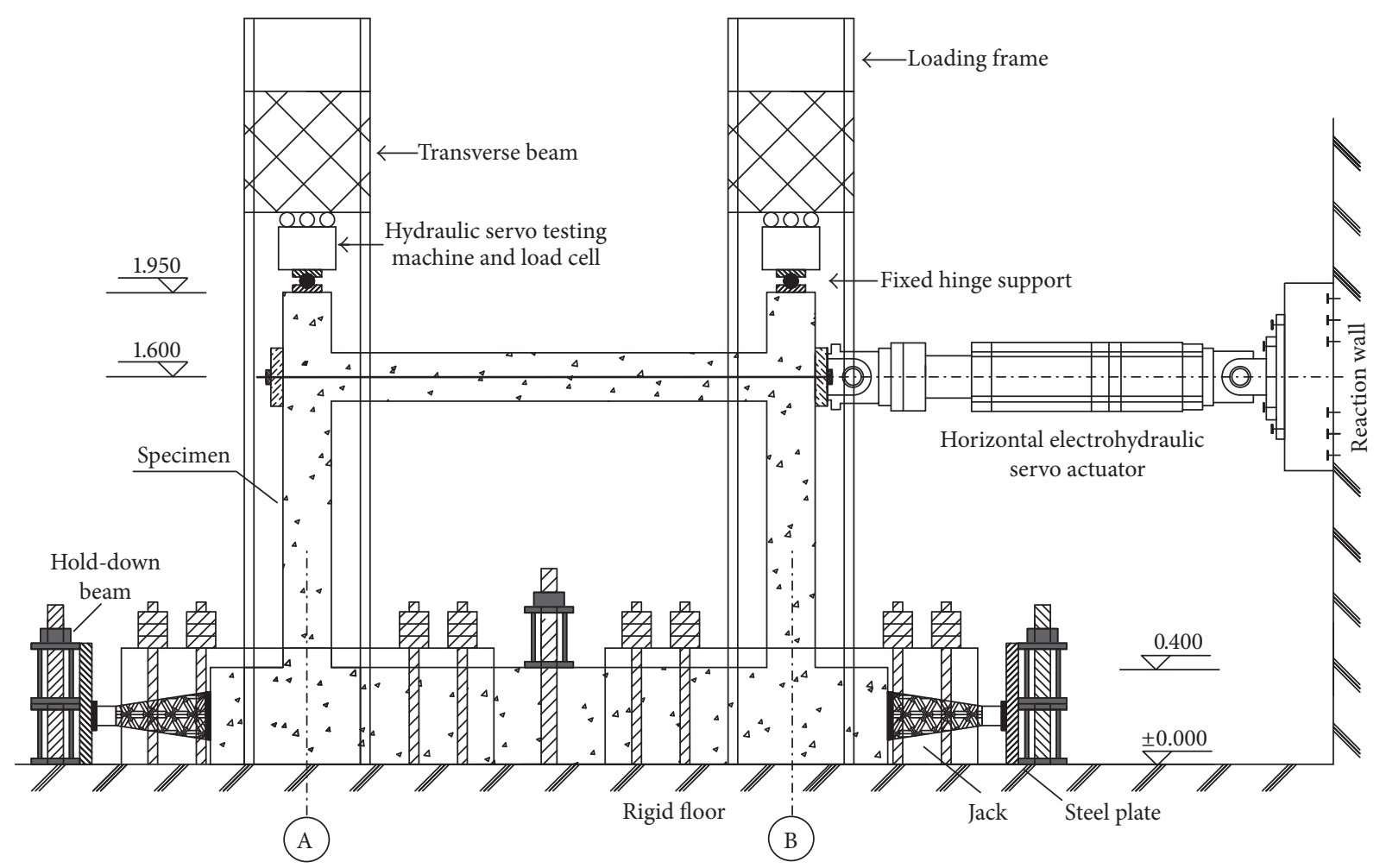

(a) Loading apparatus diagram

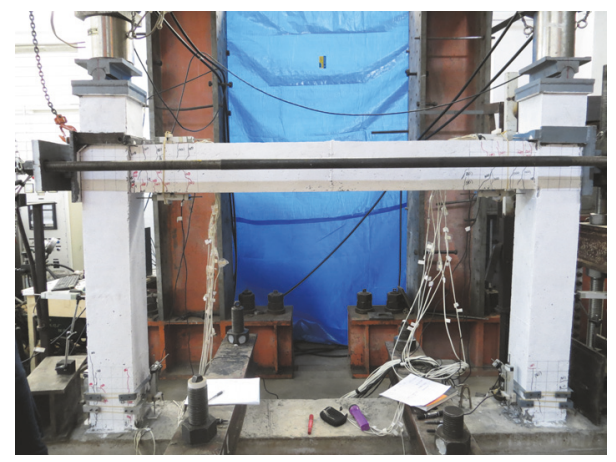

(b) Loading photo

FIGURE 3: Loading apparatus and photo.

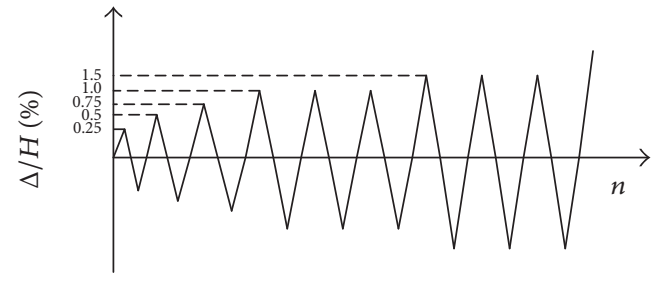

FIgure 4: Cyclic loading spectrum.

\section{Details of the Destruction Process}

This paper describes the detailed destruction process under different loading conditions, and the distribution of cracks is observed in Figure 5. In the elastic stage of loading, the columns showed no cracks on the surfaces and the total strain was very small. With an increase of the axial compression ratio, no obvious differences were observed among SRUHSC-RC-N25-I3 (N25), SRUHSC-RC-N38-I3 (N38), SRUHSC-RC-N45-I3 (N45), and SRUHSC-RC-N38I2 (N38-I2), respectively, except that the lateral force increased rapidly.

SRUHSC-SR-N25-I3. At $1 \%$ drift angle, bending cracks emerged in the end beam of N25 adjacent to the joint zone, and the column bottom exhibited lateral bending cracks. At a drift angle of $1.5 \%$, it was observed that the beam end exhibited fresh bending cracks in the range of $0-50 \mathrm{~mm}$ with widening of the original cracks. At the same time, the concrete cover was crushed slightly at the column bottom in 

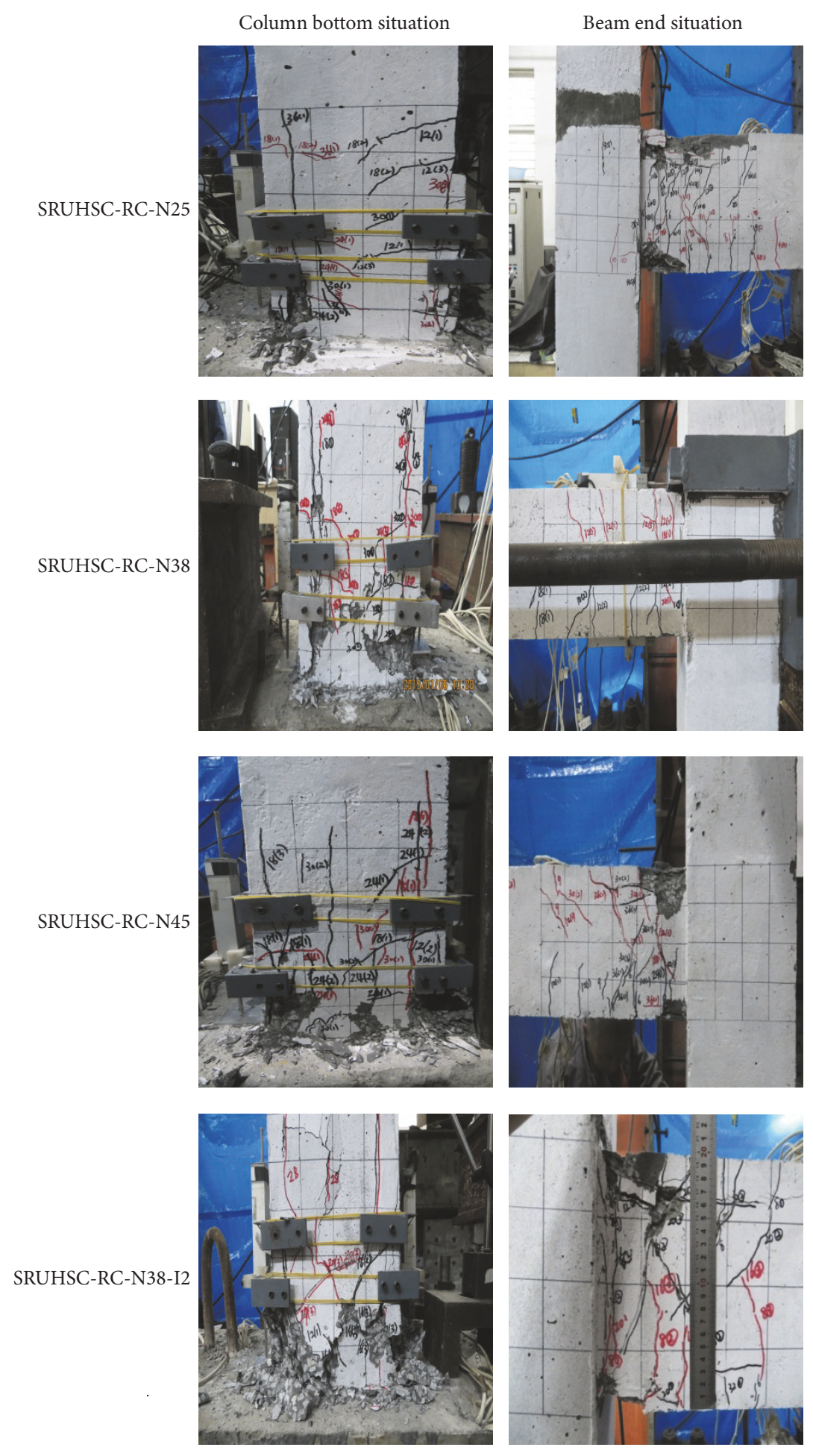

FIGURE 5: The ultimate destruction style of the beam and column.

the range of $0-20 \mathrm{~mm}$, accompanied by a crisp sound. For drift ratios of $2.5 \%$ and $3 \%$, the lateral and vertical cracks at the column bottom in the range of $0-100 \mathrm{~mm}$ interacted with each other, thus further promoting the spalling off of concrete and intensifying the destruction of the beam end, along with the development of original bending cracks, where the original cracks penetrated the whole beam section. When drift ratios of $3.5 \%$ and $4 \%$ were reached, the concrete of the column bottom in the range of $80 \mathrm{~mm}$ was crushed seriously but still maintained a monolithic section behavior, accompanied by the spalling off of the concrete cover and exposure of the longitude bar and stirrup bar at the same time. 
During the cyclic loading process, the stirrups of the column bottom were opened, and the longitude bars were bent. The test was over when the load capacity of the columns was lost. Thus, according to the above description, the damage type of the structure was mainly bending failure.

SRUHSC-SR-N38-I3. For the N38 sample, at 1\% drift ratio, the column bottom exhibited vertical and horizontal cracks, while the status of the beam end was similar to that of N25. The failure tendency of the entire structure was similar to the former, but the concrete cover of the column bottom was crushed in the range of $0-50 \mathrm{~mm}$. When a drift angle of $2 \%$ was reached, original cracks of the specimen were clearly observed and more fresh ones appeared. Meanwhile, the new vertical cracks appeared close to the core of the section. At $2.5 \%$ drift ratio, the bottom of the column exhibited a large number of horizontal and vertical cracks, as well as inclined cracks between two types of crack regions, therefore further accelerating the damage rate of the concrete structure. At $3 \%$ drift ratio, the vertical and diagonal cracks developed rapidly and were promoted to be further destroyed in the range of the core zone. The load capacity of the specimens decreased significantly until the test was over. From the above description, the damage styles of the structure were bending and bond failure.

SRUHSC-SR-N45-I3. For the N45 sample, at 1\% drift ratio, the columns did not only generate new vertical cracks but also exhibited inclined cracks in the range of 100 to $250 \mathrm{~mm}$. Meanwhile, the amount of cracks, which were generated at the end of the beam, reduced gradually, and the space between the cracks became much larger. At 2.5\% drift ratio, the column bottom exhibited horizontal and diagonal cracks in the range of 0 to $150 \mathrm{~mm}$, and the core region exhibited new vertical cracks, and the original cracks continued to extend, with the concrete cover partially spalling off. Compared with $\mathrm{N} 25$ and N38, the beam damage was weakened and the development of cracks decreased. At 3\% drift ratio, the vertical cracks continued to propagate, and the width of the original diagonal cracks widened and the concrete cover was destroyed severely. At the beginning of the third cycle at the same amplitude, the columns lost load capacity, which illustrated that the experiment was over. The destruction style of the structure was the interaction of bond splitting and bending failure.

SRUHSC-SR-N25-I2. At 1\% drift ratio, horizontal and vertical cracks occurred at the same time. Moreover, vertical cracks emerged in the core area of the column section, and this situation was earlier than that of N38. At 1.5\% drift ratio, the column bottom exhibited several diagonal cracks in the range of 0 to $100 \mathrm{~mm}$ and horizontal cracks in the range of 50 to $100 \mathrm{~mm}$. Meanwhile, tiny cracks emerged in the beam end. At $2 \%$ drift ratio, partial concrete was crushed at the bottom of column, and the original diagonal cracks in the 45-degree direction continued to extend and fresh cracks appeared parallel to these diagonal cracks. The destruction degree for SRUHSC-RC-N38-I2 (N38-I2) was more serious than that for N38. For $2.5 \%$ drift ratio, with the procession of the cyclic loading, the column bottom was destroyed more seriously and rapidly than N38, but the beam end was destroyed more and more lightly than N38, and the width of the cracks became smaller than the former. For drift ratios of 3\%-3.5\%, vertical and diagonal cracks kept on developing, and the variation of the horizontal cracks was not obvious. The load capacity decreased rapidly until loading was finished. A distribution was observed in the forms of the cracks, and the vertical and diagonal cracks had a dramatic influence on the column damage. Thus, the damage type of the structure belonged to split failure and shear failure.

\section{Analyses of Experimental Results}

5.1. Hysteretic Loop. The relationship between the lateral load $(F)$ and the lateral displacement $(\Delta)$ constitutes the hysteretic loop under quasi-static cyclic loading, which is an important factor in seismic behavior analysis. The details are shown in Figure 6.

The hysteretic behavior of the entire structure appears to exhibit three phases: (1) in the initial stage, it is characterized by full participation of both confined core concrete and unconfined cover concrete, and the loops exhibit mostly a linear relationship. The loops surrounding the area are narrow and small, implying that the entire structure is in the range of elastic stage. The main reason is that the frame structures do not generate cracks in this stage, and the strains mainly rely on the deformation of the entire structure; (2) stable behavior with deformation is contributed primarily by the steel and longitudinal yielding, as well as concrete cracking. The loop grows much larger than the former. In this process, the beam end and column bottom of the frames generate tiny cracks, along with opening of the cracks and the closing process. Seismic energy is dissipated to a certain extent. Therefore, the seismic energy dissipation capacity of the structure itself should be enhanced; (3) in the final failure stage, the beginning of the stable stage is typically marked by crushing and spalling of the unconfined cover concrete, and maximum lateral force is achieved prior to crushing of the cover concrete. As the amplitude of the drift is increased, the hysteretic loop area enlarges and forms a plump spindle. The hysteretic loops gradually rotate towards the horizontal direction and the loop area expands gradually, which means that the columns have reached their yield drift. Moreover, the structures have entered into the plastic phase. Hereafter, the concrete of the beam end and the column bottom is crushed, and the reinforced bars yield successively. The residual deflection becomes more obvious, and the lateral load at the same drift rotation tends to decrease obviously with increasing cycle number.

5.2. Skeleton Curves. The skeleton curves reflect the relationship between the peak loads and corresponding displacements from the hysteresis loops of the specimens, which is the envelope curve obtained by connecting the peak point of each loading increment on the hysteretic curves [29]. The skeleton curves are shown in Figure 7. For different axial compression ratios, the variation tendency of the skeleton 


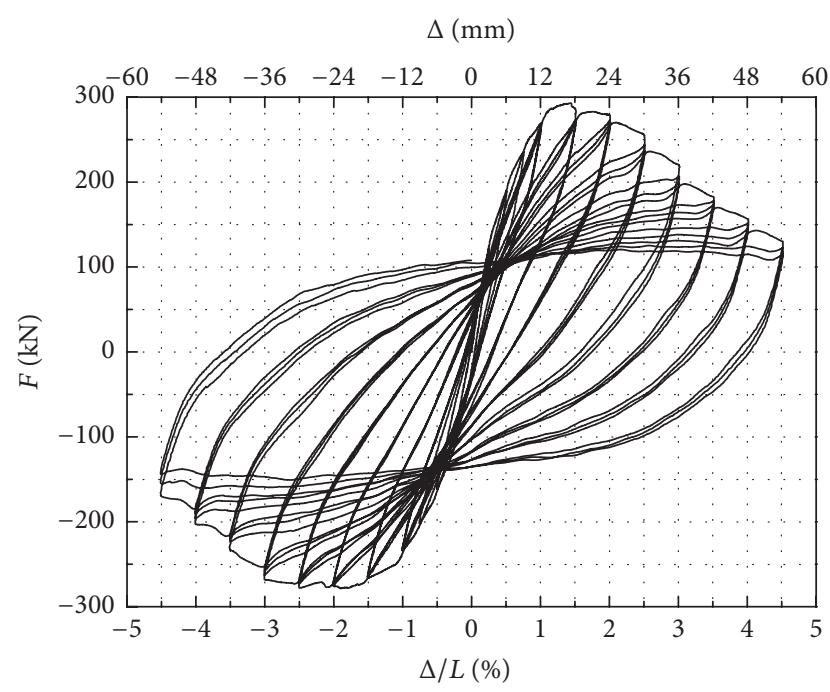

— SRUHSC-RC-N25-I3

(a) SRUHSC-RC-N25-I3

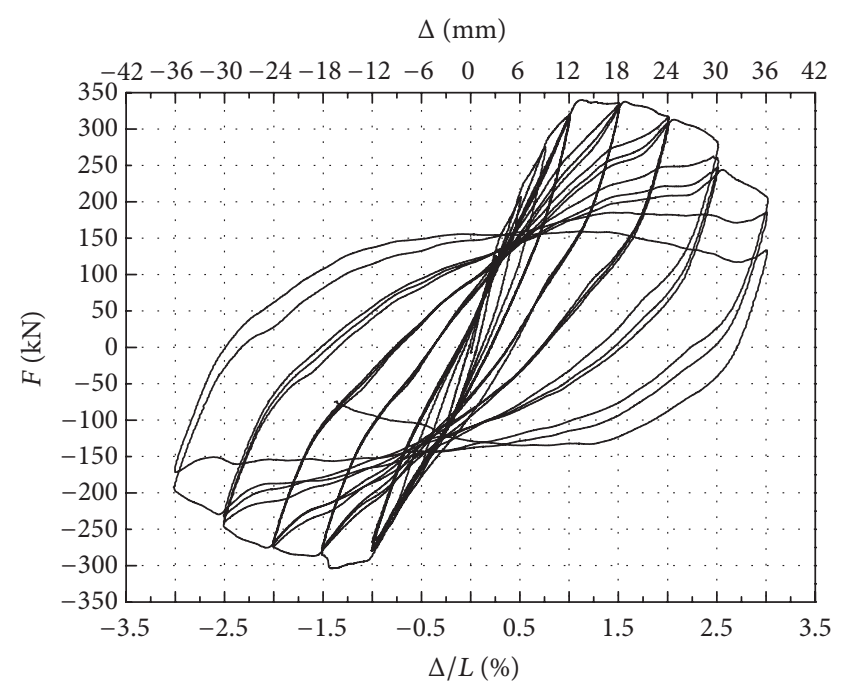

— SRUHSC-RC-N45-I3

(c) SRUHSC-RC-N45-I3

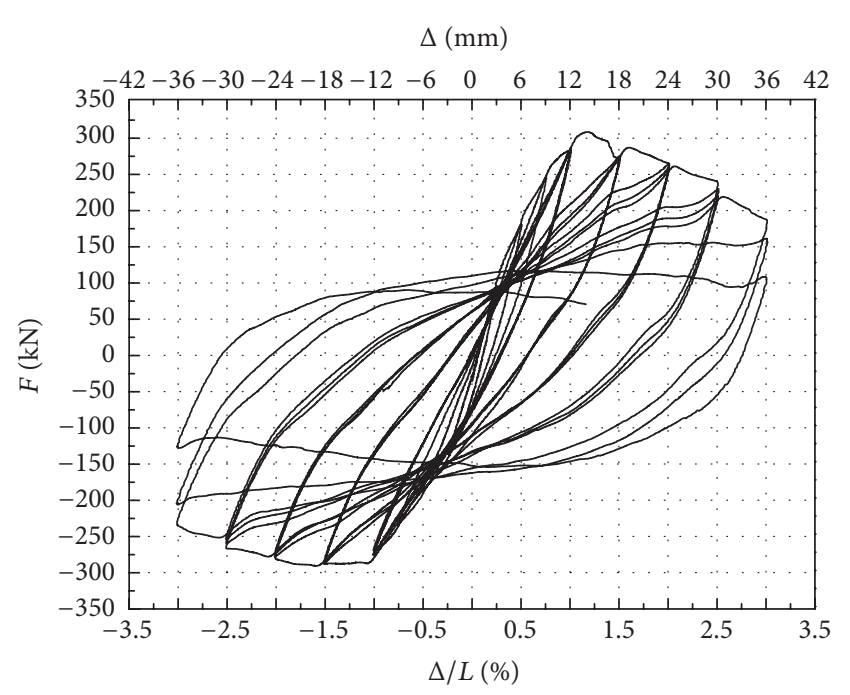

— SRUHSC-RC-N38-I3

(b) SRUHSC-RC-N38-I3

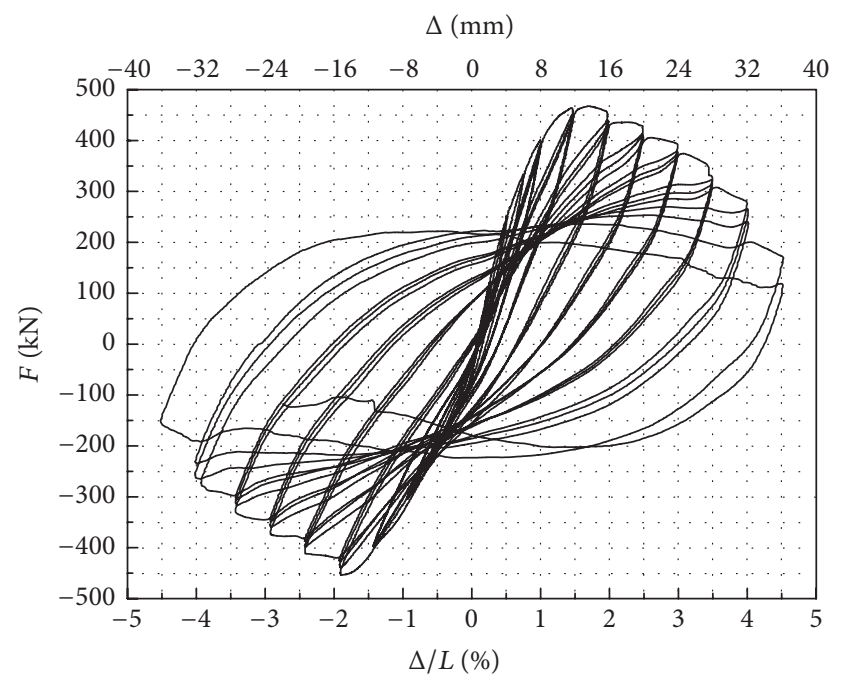

- SRUHSC-RC-N38-I2

(d) SRUHSC-RC-N38-I2

FIGURE 6: Hysteretic curve of the SRUHSC frame.

curves is exhibited in Figure 7(a). At the early stage of loading, the shape of the skeleton curve is very similar to each other, and as the axial compression ratio is increased, the summit load of the specimens is gradually enhanced, but the ascending and descending stages of the skeleton curve become steeper, illustrating that the variation of the load capacity is accelerating. The main reason can be elaborated in two aspects. First, the higher the axial compression ratio is, the faster the generation and development of the vertical cracks are, which have a direct influence on the integrity of the concrete section, thus decreasing the loading capacity of the structure. Second, with increasing axial compression ratio, the failure of the frame structure is mainly dominated by the damage of the column bottom, and the variation of the failure mode also accelerates the destruction speed of the entire structure from ductile failure to brittle failure.

Figure 7(b) shows that the skeleton curves of the two specimens exhibit obvious differences; that is, the lower the shear span ratio is, the greater the slope of the load capacity is. The main reason is that the decrease of the shear span ratio leads to an increase in the linear stiffness, as well as an enhancement of the lateral resisting stiffness. Thus, the horizontal load will be greater, and the structure with a small shear span ratio is destroyed more rapidly.

5.3. Ductility Factor. Ductility factor is used to evaluate the deformation capacity and seismic behavior of frame structures. The drift ductility coefficient is based on the equivalent energy method [22], as shown in Figure 8, where 


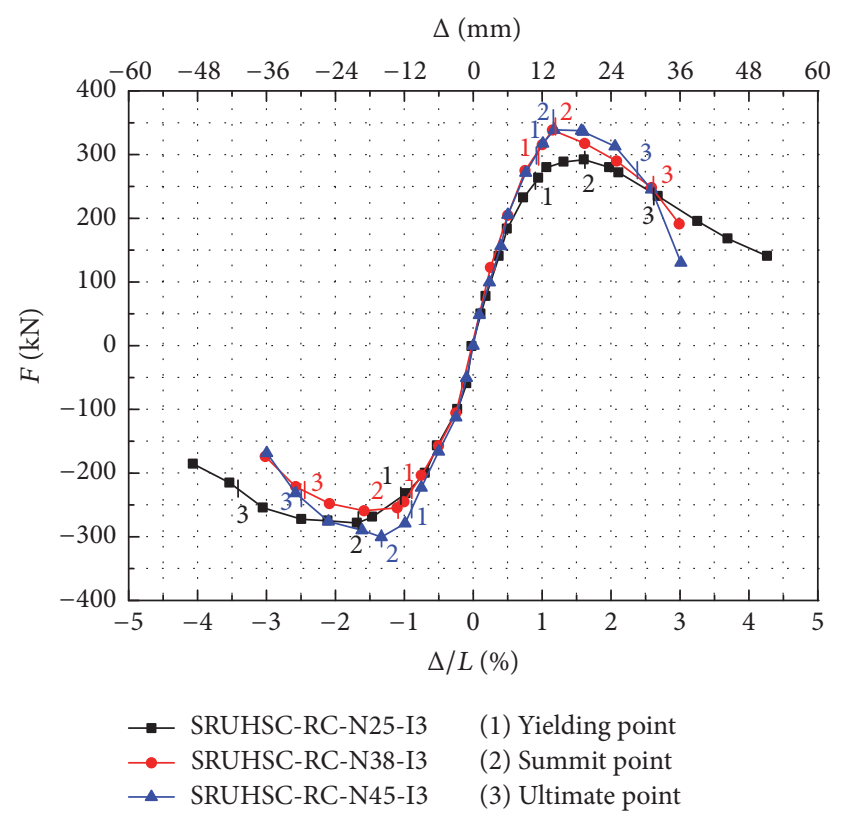

(a) Skeleton curves of different axial compression ratios

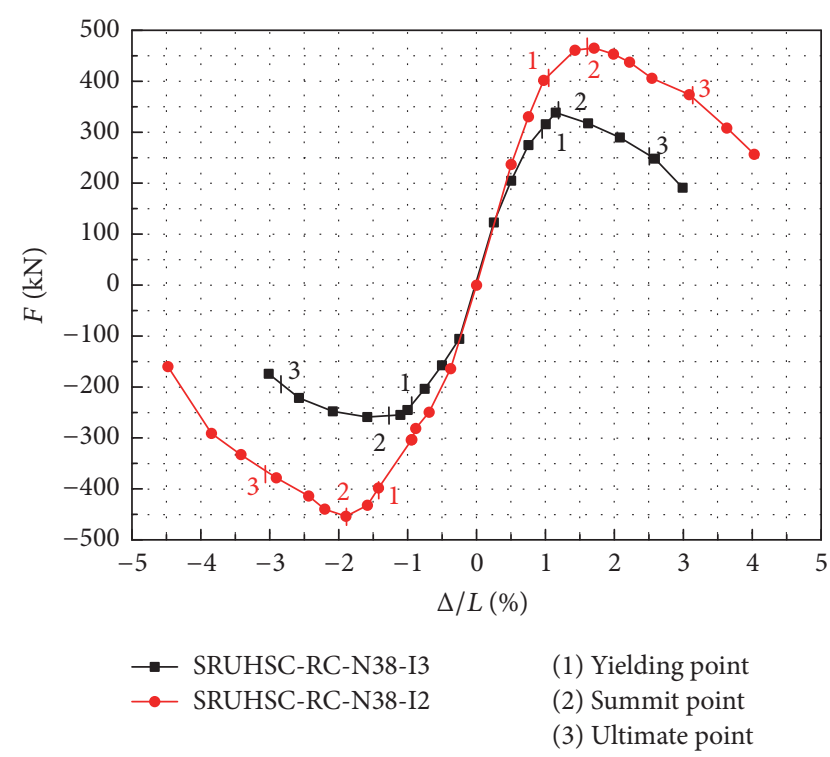

(b) Skeleton curves of different shear span ratios

FIGURE 7: Skeleton curve comparison of the SRUHSC frame.

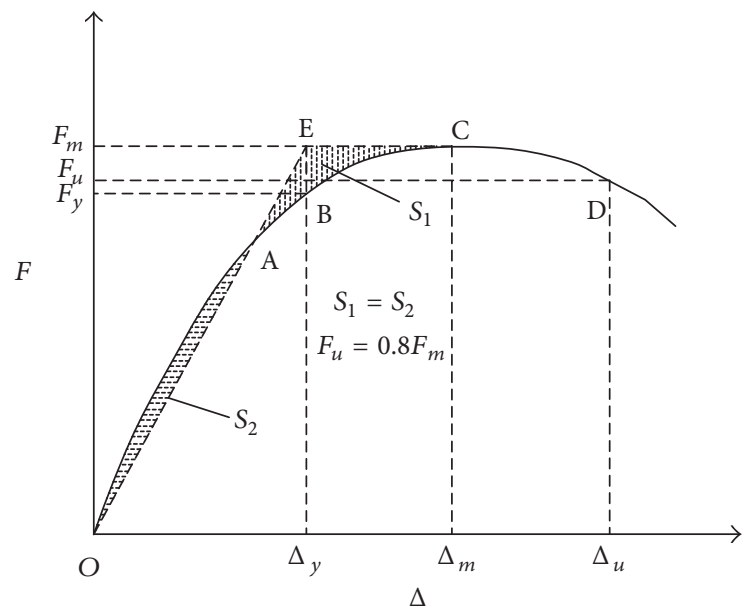

FIGURE 8: Sketch of the energy equivalence method.

the ductility coefficient of frames can be determined by the ultimate displacement to the yield displacement ratio. The expression is as follows:

$$
\lambda=\frac{\left|\Delta_{u}\right|+\left|-\Delta_{u}\right|}{\left|\Delta_{y}\right|+\left|-\Delta_{y}\right|},
$$

where $\Delta_{u}$ is the ultimate displacement and $\Delta_{y}$ is the yield drift displacement.

In the test, the ultimate drift takes $80 \%$ of the ultimate load corresponding to the drift, and the yield drift directly corresponds to the yield load. From the skeleton curve, the value of the loading is obviously divided into yield, summit, and ultimate load point. The detailed values of each stage are shown in Table 5. Although the ductility coefficient is relatively small, the story drift angle of elastic-plastic is between $1 / 29$ and $1 / 45$, which meets the requirement of the norm, that is, more than $1 / 50[23,30]$. Meanwhile, it is noticed from Table 5 that there is a certain distinction between the value of the positive and negative load in that the positive loading value is slightly higher than the value of the reverse loading. The main reason is that the specimens possess damage and residual strain after positive loading, and in reverse loading, structural damage continues to increase and also needs to offset the residual deformation of the structure at the same time. Therefore, the distinction of push and pull loading is rational.

5.4. Deterioration of Stiffness. Stiffness degradation is another index for characterizing the seismic behavior of structures [18]. This degradation is often regarded as a key index for evaluating the extent of structure failure, and the stiffness gradually deteriorates as the lateral drift increases in the quasi-static test load. A comparison of the stiffness deterioration is made between different axial compression ratios and shear span ratios to further analyze the behavior. Figure 10 displays the secant stiffness of each frame during the first cycle of each amplitude loading. The secant stiffness formula is expressed as follows:

$$
K_{i}=\frac{\left|+F_{i}\right|+\left|-F_{i}\right|}{\left|+\Delta_{i}\right|+\left|-\Delta_{i}\right|}
$$

where $F$ is the peak load at each hysteresis loop and $\Delta$ is the peak drift corresponding to the peak load. + and - represent the positive and negative directions, respectively.

Figure 9(a) shows relationships of the stiffness degradation for different axial compression ratios. The N38 and 
TABLE 5: The skeleton curve characteristic value.

\begin{tabular}{|c|c|c|c|c|c|c|c|c|c|}
\hline \multirow{2}{*}{ Specimen } & \multirow{2}{*}{ Loading direction } & \multicolumn{2}{|c|}{ Yielding point } & \multicolumn{2}{|c|}{ Summit point } & \multicolumn{2}{|c|}{ Ultimate point } & \multirow{2}{*}{$\begin{array}{c}\text { Ductility } \\
\lambda\end{array}$} & \multirow{2}{*}{$\begin{array}{l}\text { Ultimate drift ratio } \\
\qquad R_{u}\end{array}$} \\
\hline & & $F_{y}(\mathrm{KN})$ & $\Delta_{y}(\mathrm{~mm})$ & $F_{m}(\mathrm{KN})$ & $\Delta_{m}(\mathrm{~mm})$ & $F_{u}(\mathrm{KN})$ & $\Delta_{u}(\mathrm{~mm})$ & & \\
\hline \multirow{2}{*}{ SRUHSC-RC-N25-I3 } & + & 256.6 & 10.6 & 292.66 & 19.24 & 234.13 & 32.47 & 3.06 & $1 / 37$ \\
\hline & - & -236.66 & -12.62 & -277.89 & -20.27 & -222.3 & -41.23 & 3.27 & $1 / 29$ \\
\hline \multirow{2}{*}{ SRUHSC-RC-N38-I3 } & + & 277.28 & 11.37 & 306.7 & 14.78 & 245.36 & 27.06 & 2.38 & $1 / 45$ \\
\hline & - & -254.7 & -10.86 & -289.47 & -15.03 & -231.5 & -33.6 & 3.09 & $1 / 36$ \\
\hline \multirow{2}{*}{ SRUHSC-RC-N45-I3 } & + & 301.84 & 11.1 & 339.02 & 14.11 & 271.22 & 28.86 & 2.6 & $1 / 42$ \\
\hline & - & -271.93 & -11.4 & -300.42 & -16 & -240.3 & -29.9 & 2.62 & $1 / 40$ \\
\hline \multirow{2}{*}{ SRUHSC-RC-N38-I2 } & + & 417.87 & 8.87 & 465.17 & 13.66 & 372.1 & 25.05 & 2.82 & $1 / 32$ \\
\hline & - & -399.59 & -11.37 & -453.85 & -15.14 & -363.1 & -25.25 & 2.22 & $1 / 31$ \\
\hline
\end{tabular}

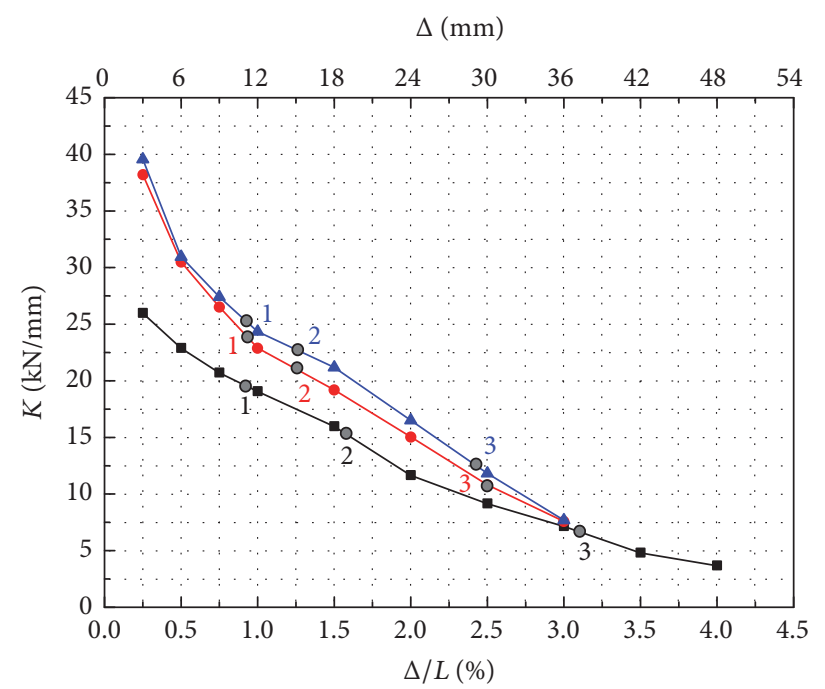

$\because$ SRUHSC-RC-N25-I3
$\because$ SRUHSC-RC-N38-I3
$\because$ SRUHSC-RC-N45-I3

(1) Yielding point

(2) Summit point

(3) Ultimate point

(a) Secant stiffness of different axial compression ratios

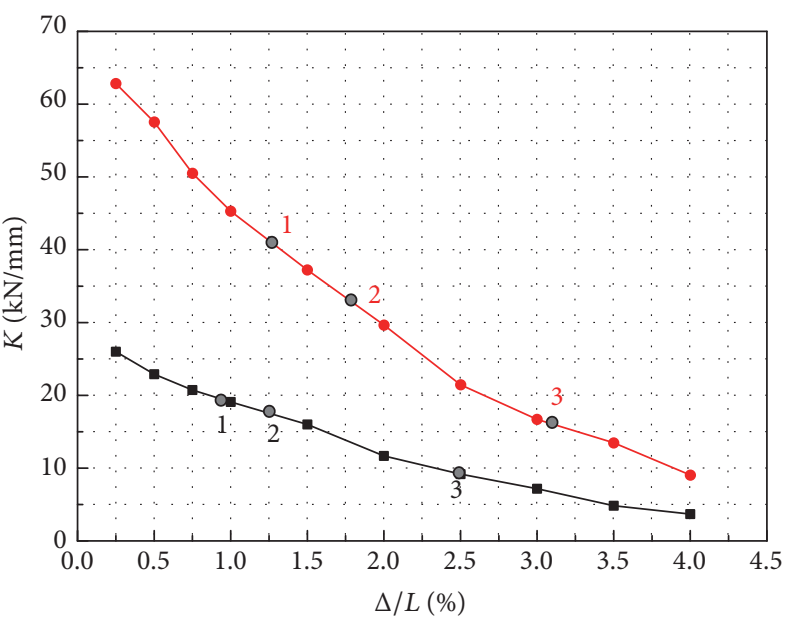

- SRUHSC-RC-N38-I3

(1) Yielding point

(2) Summit point

(3) Ultimate point

(b) Secant stiffness of different shear span ratios

FIGURE 9: Secant stiffness degradation of the frame.

N45 curve shapes are extremely similar, which illustrates that increasing the axial compression to a certain extent has a tiny influence on stiffness degradation. However, the initial stiffness of the N25 specimen shows an obvious difference. The main reason is that the higher the axial compression ratio is, the greater the constraint of the column is and the greater the initial stiffness is. As the axial compression increases, vertical cracks rapidly develop in the process of loading. Meanwhile, the diagonal cracks gradually play a role in accelerating the damage of the column section; the more serious the compressive failure of the contact surface of the horizontal and diagonal cracks is, the faster the strength degradation is.

A comparison of the skeleton curves of different shear span ratios is exhibited in Figure 9(b). The distinction between N38 and N38-I2 is obvious, where the N38 specimen belongs to bending and bond failure and the N38-I2 specimen belongs to splitting and shear failure. The horizontal cracks change from edge to center on the surface of the column, and vertical and diagonal cracks develop in the section core, which rapidly decreases the restraining effect of stirrups and steel for the core area of the concrete, further accelerating the failure rate of the section.

5.5. Energy Dissipation Capacity. The dissipation energy capacity of the structure at the drift angle is measured by the area of stress to strain enclosed. The energy dissipation capacity of the structure is closely related to the area of the hysteresis loop [31]; that is, the bigger the area is, the greater the absorbing energy is. The area diagram is shown in Figure 10, and the area surrounded by the ABCF curve is the energy dissipation capacity of the structures. Figure 11 shows the curve tendency of the dissipation capacity.

In the initial loading phase, the curves of energy dissipation are very close to that before cracks occur, and the energy dissipation capacity of the structure mainly relies on the distortion of the entire structure. When the elastic-plastic deformation stage is reached, a distinction of the energy 


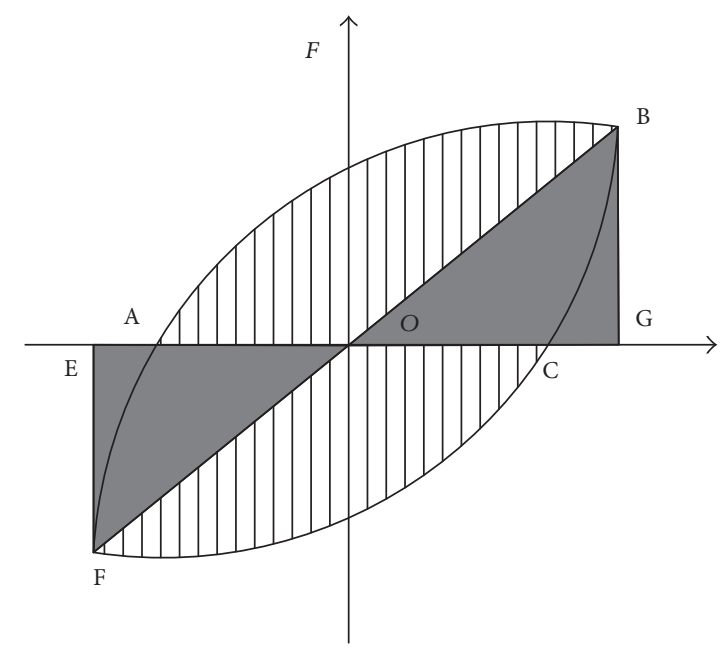

FIGURE 10: The dissipation capacity area.

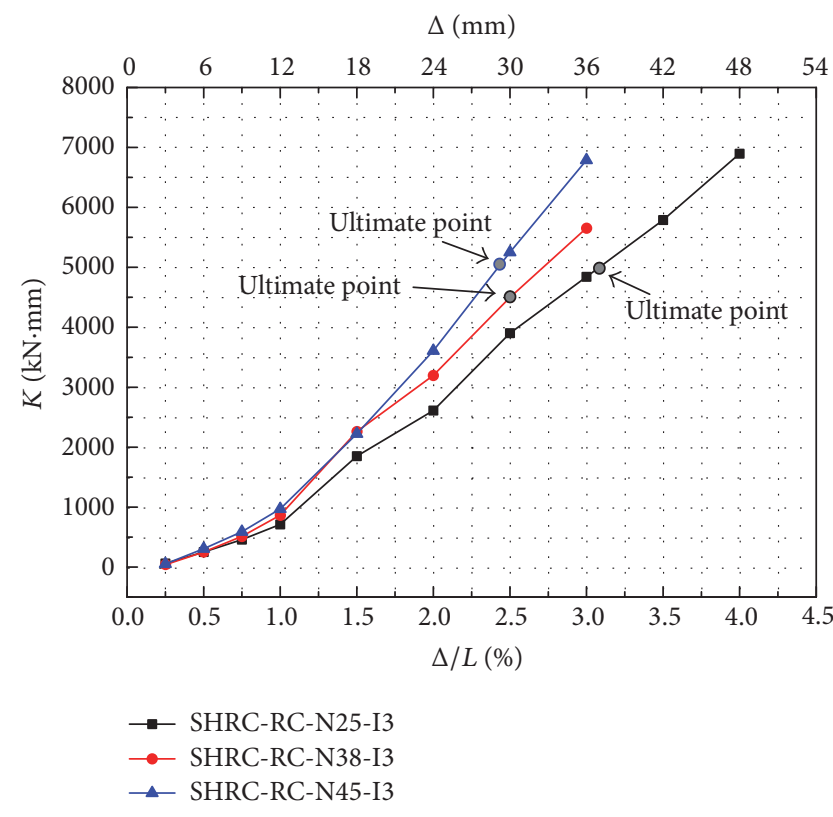

(a) Energy dissipation curves of different axial compression ratios

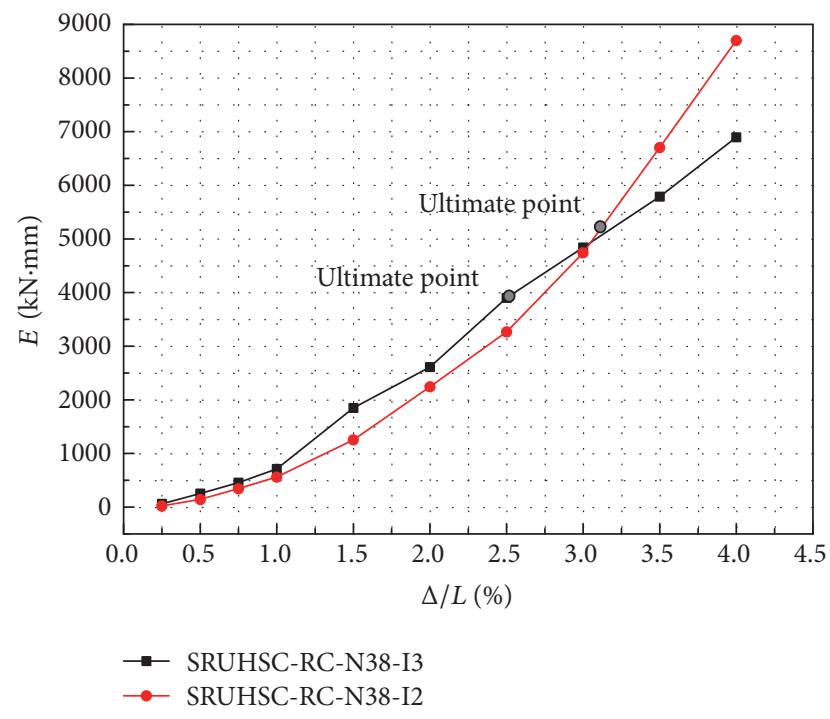

(b) Energy dissipation curves of different shear span ratios

FIGURE 11: Energy dissipation of the frame.

dissipation capacity is observed, and the cracks of the beam end dissipate a small amount of energy, whereas columns become the major energy dissipation components. With the increase of the axis pressure ratio and decrease of the shear span ratio, the initial stiffness of the structures increases. Meanwhile, failure becomes more serious, causing the test to finish. However, in the process, the hysteresis loop area increases and the absorption ability of the energy improves. The main reason is that the rate of force improving is greater than that of stiffness degradation.

5.6. Residual Displacements. The residual drift is taken as the drift at the point of zero lateral force at the end of the first cycle of each imposed lateral drift level [32], as shown in
Figure 12(a). At the preliminary phase of $1 \%$, the residual force is similar to each other, which may be attributed to the elastic variation of the entire structure. Cracks occur on the surface of the concrete cover, so the residual drift is very tiny; correspondingly, the residual drift ratio is also very small, as shown in Figures 12(b) and 12(c). Nevertheless, the distinction of the residual force increases gradually for the $1 \%-1.5 \%$ drift ratio. This phase belongs to the elastic-plastic phase, and the concrete cover exhibits obvious cracks. The residual force and drift show obvious variations; moreover, the higher the axial compression ratio is, the larger the residual force is, and it can be concluded that the axial load significantly affects the residual force of the SRUHSC frames. 


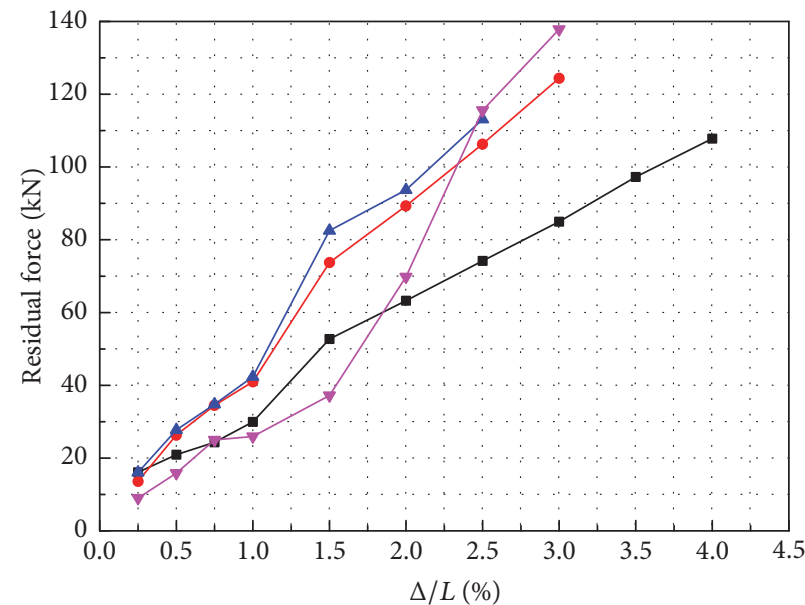

$\begin{array}{ll}\rightarrow \text { SRUHSC-RC-N25-I3 } & \rightarrow \text { SRUHSC-RC-N45-I3 } \\ \rightarrow \text { SRUHSC-RC-N38-I3 } & \rightarrow \text { SRUHSC-RC-N38-I2 }\end{array}$

(a) Residual force comparison

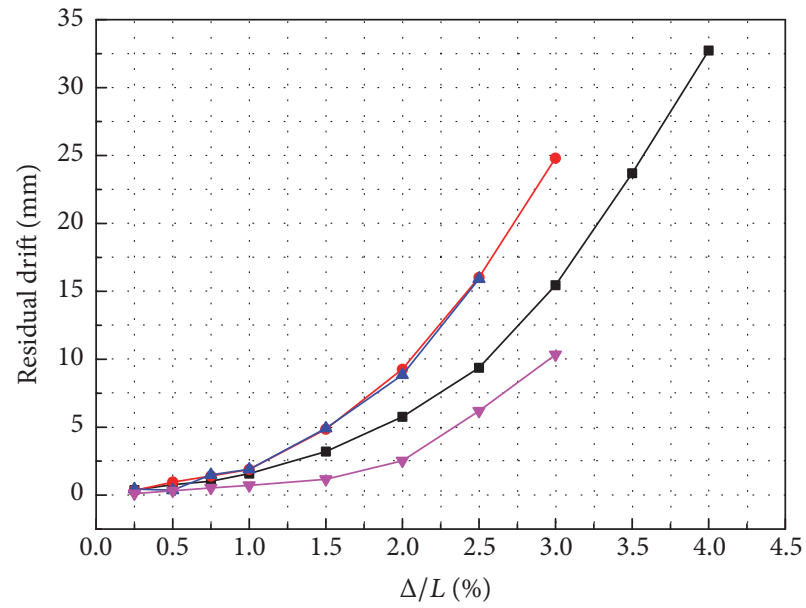

$\rightarrow$ SRUHSC-RC-N25-I3 $\rightarrow$ SRUHSC-RC-N45-I3 $\longrightarrow$ SRUHSC-RC-N38-I3 $\rightarrow$ SRUHSC-RC-N38-I2

(b) Residual drift comparison

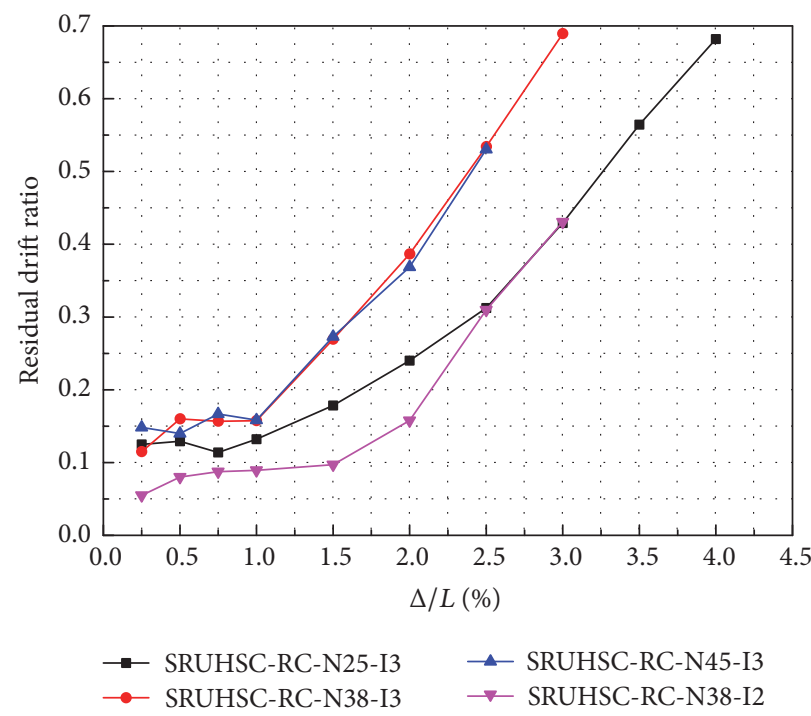

(c) Comparison of the residual drift ratio

Figure 12: Comparison of the residual force and drift.

Beyond $1.5 \%$, the variation rate of the residual force is almost equivalent, except for N38-I2. This stage shows the concrete cover spalling off, and the longitude rebar and steel shape start to yield. Partial concrete at the bottom of the column is crushed with the increase of the cyclic loading amplitude. Meanwhile, the residual drift and drift ratio show significant improvement, but as shown in Figures 12(b) and 12(c), the residual drift and drift ratio of N38 and N45 are in close proximity. It is illustrated that the axial compression ratio, which is greater than second seismic grade, has a slight influence on the aspect of residual drift and the drift ratio. This SRUHSC frame structure meets the specification requirements [19] and is also in accordance with the seismic code of the column.

\section{Conclusions}

This paper mainly discussed the seismic behavior of steel reinforced ultrahigh strength concrete (SRUHSC) frame in reverse cyclic loading test. The influences of the axial compression ratio and shear span ratio were specifically investigated. Based on the test results and previous analysis, the following conclusions were reached:

(1) In the damage process, the plastic hinges at the beam end and column bottom possessed a desirable energy dissipation capacity. The columns served as the primary energy dissipation components, which should meet the requirements of the strong column-weak 
beam and strong joint-weak component principles. Moreover, it was also observed that the higher the axial compression ratio, the greater damage range the column bottom will experience, and thus the more ease the plastic hinge will emerge. Meanwhile, it would be more difficult for the formation of the plastic hinge with a smaller shear span ratio, and consequently, the frame was prone to failure, exhibiting an undesirable nonductile behavior.

(2) With the increase of the axial compression ratio, the failure mode of the columns changed from bending failure to bending and bond failure and further extended to bending and bond splitting failure. As for the influence of the shear span ratio, a value of 2 usually corresponded to the shear and splitting failure mode, while the bending failure mechanism tended to dominate at beam ends with a gradual decrease in the failure tendency and larger crack spacing. It is reasonable to conclude that the failure mode of the SRUHSC frame was sensitive to the variation of the axial compression ratio and shear span ratio.

(3) For axial compression ratio of more than 0.75 , which is the secondary magnitude of seismic resistance, the distinctions of seismic coefficient, residual force, and drift were not obvious. It was illustrated that an axial compressive ratio of 0.75 was the critical value for second seismic grade in the SRUHSC frame structure, which was in accordance with the specification of reinforced concrete structures [23].

(4) Columns were likely to experience more severe deterioration under a higher axial compression ratio, which was accompanied by the failure of beam end weakening. When the shear span ratio was reduced, a change of the crack direction occurred and the section stiffness further deteriorated. Failure would be inevitably expected.

(5) The ultimate drift angle of SRUHSC frame was less than $1 / 50$, which met the requirements of the code for seismic design of buildings [24].

(6) The effect of shear span ratio on stiffness deterioration as well as energy dissipation capacity outweighed that of the axial compression ratio for the frame structure. A decreasing shear span ratio corresponded to a larger hysteresis loop area, signifying the fact that more seismic energy was absorbed.

\section{Conflicts of Interest}

The authors declare that they have no conflicts of interest.

\section{Acknowledgments}

The work was supported by the National Natural Science Fund (Grant no. 51178078) and their support is gratefully acknowledged.

\section{References}

[1] D. Yao, J. Jia, F. Wu, and F. Yu, "Shear performance of prestressed ultra high strength concrete encased steel beams," Construction and Building Materials, vol. 52, pp. 194-201, 2014.

[2] B. A. Graybeal, Structural Behavior of Ultra-High Performance Concrete Prestressed I-Girders, Federal Highway Administration, Washington, DC, USA, 2006.

[3] B. A. Graybeal, "Flexural behavior of an ultrahigh-performance concrete I-girder," Journal of Bridge Engineering, vol. 13, no. 6, pp. 602-610, 2008.

[4] E. Steinberg, "Structural reliability of prestressed UHPC flexure models for bridge girders," Journal of Bridge Engineering, vol. 15, no. 1, pp. 65-72, 2010.

[5] L. Hussein and L. Amleh, "Structural behavior of ultra-high performance fiber reinforced concrete-normal strength concrete or high strength concrete composite members," Construction and Building Materials, vol. 93, pp. 1105-1116, 2015.

[6] M. M. Attard and S. Setunge, "Stress-strain relationship of confined and unconfined concrete," ACI Materials Journal, vol. 93, no. 5, pp. 432-441, 1996.

[7] D. C. Kent and R. Park, "Flexural members with confined concrete," Journal of the Structural Division, vol. 97, no. 7, pp. 1969-1990, 1971.

[8] R. Park, M. J. N. Priestley, and W. D. Gill, "Ductility of squareconfined concrete columns," ASCE Journal of the Structural Division, vol. 108, no. 4, pp. 929-950, 1982.

[9] B. D. Scott, R. Park, and M. J. N. Priestley, "Stress-strain behavior of concrete confined by overlapping hoops at low and high strain rates," Journal of the American Concrete Institute, vol. 79, no. 1, pp. 13-27, 1982.

[10] Eurocode 4, Design of Composite Steel and Concrete Structures, Part 1.1: General Rules and Rules for Buildings, Brussels: Commission of European Communities, March 1992.

[11] Load and Resistance Factor Design Specification for Structural Steel Buildings, American Institution of Steel Construction (AISC), Chicago, Ill, USA, 1993.

[12] Professional Standard of the People's Republic of China, YB 9082-2006 Technical Specification of Steel-Reinforced Concrete Structures, Metallurgical Industry Press, Beijing, China, 2012.

[13] Professional Standard of the People's Republic of China, JBJ 138-2001 Technical Specification of Steel Reinforced Concrete Composite Structures, China Architecture \& Building Press, Beijing, China, 2002.

[14] P. Gajalakshmi and H. J. Helena, "Behaviour of concrete-filled steel columns subjected to lateral cyclic loading," Journal of Constructional Steel Research, vol. 75, pp. 55-63, 2012.

[15] M. Moretti and T. P. Tassios, "Behaviour of short columns subjected to cyclic shear displacements: Experimental results," Engineering Structures, vol. 29, no. 8, pp. 2018-2029, 2007.

[16] J. Zhang and J. Jia, "Experimental study on seismic behavior of composite frame consisting of SRC beams and SRUHSC columns subjected to cyclic loading," Construction and Building Materials, vol. 125, pp. 1055-1065, 2016.

[17] C. Chen, C. Wang, and H. Sun, "Experimental study on seismic behavior of full encased steel-concrete composite columns," Journal of Structural Engineering, vol. 140, no. 6, Article ID 04014024, 2014.

[18] W. Xu, L.-H. Han, and W. Li, "Seismic performance of concreteencased column base for hexagonal concrete-filled steel tube: Experimental study," Journal of Constructional Steel Research, vol. 121, pp. 352-369, 2016. 
[19] L.-H. Han, W.-D. Wang, and X.-L. Zhao, "Behaviour of steel beam to concrete-filled SHS column frames: Finite element model and verifications," Engineering Structures, vol. 30, no. 6, pp. 1647-1658, 2008.

[20] A. U. Qazi, L. Ye, and X. Lu, "Passive control reinforced concrete frame mechanism with high strength reinforcements and its potential benefits against earthquakes," Tsinghua Science and Technology, vol. 11, no. 6, pp. 640-647, 2006.

[21] W. Li, Q.-N. Li, and W.-S. Jiang, "Parameter study on composite frames consisting of steel beams and reinforced concrete columns," Journal of Constructional Steel Research, vol. 77, pp. 145-162, 2012.

[22] C. Jin, Z. Pan, S. Meng, and Z. Qiao, "Seismic behavior of shearcritical reinforced high-strength concrete columns," Journal of Structural Engineering (United States), vol. 141, no. 8, Article ID 04014198, 2015.

[23] Chinese Standard Code for Seismic Design of Buildings (GB 50011), Chinese Building Press, Beijing, China, 2010.

[24] Technical Specification of Steel-Reinforced Concrete Structures (YB9082-2006), Metallurgical Industry Press, Beijing, China, 2012.

[25] Specification of Testing Methods for Earthquake Resistant Building (JGJ 101-1996), China Architecture \& Building Press, Beijing, China, 1997.

[26] H. Jiang, X. Liu, and J. Mao, "Full-scale experimental study on masonry infilled RC moment-resisting frames under cyclic loads," Engineering Structures, vol. 91, pp. 70-84, 2015.

[27] F. Légeron and P. Paultre, "Behavior of high-strength concrete columns under cyclic flexure and constant axial load," ACI Structural Journal, vol. 97, no. 4, pp. 591-601, 2000.

[28] R. N. F. Carmo, H. Costa, and T. Simões, "Influence of concrete strength and transverse reinforcement yield strength on behavior of high- strength concrete columns," ACI Structural Journal, vol. 98, no. 4, pp. 490-501, 2001.

[29] H. Ma, J. Xue, X. Zhang, and D. Luo, "Seismic performance of steel-reinforced recycled concrete columns under low cyclic loads," Construction and Building Materials, vol. 48, pp. 229-237, 2013.

[30] M. N. Bugeja, J. M. Bracci, and W. P. Moore Jr., "Seismic behavior of composite RCS frame systems," Journal of Structural Engineering, vol. 126, no. 4, pp. 429-436, 2000.

[31] A. S. Tawfik Essa, M. R. Kotp Badr, and A. H. El-Zanaty, "Effect of infill wall on the ductility and behavior of high strength reinforced concrete frames," HBRC Journal, vol. 10, no. 3, pp. 258-264, 2014.

[32] O. Youssf, M. A. ElGawady, and J. E. Mills, "Experimental investigation of crumb rubber concrete columns under seismic loading," Structures, vol. 3, pp. 13-27, 2015. 

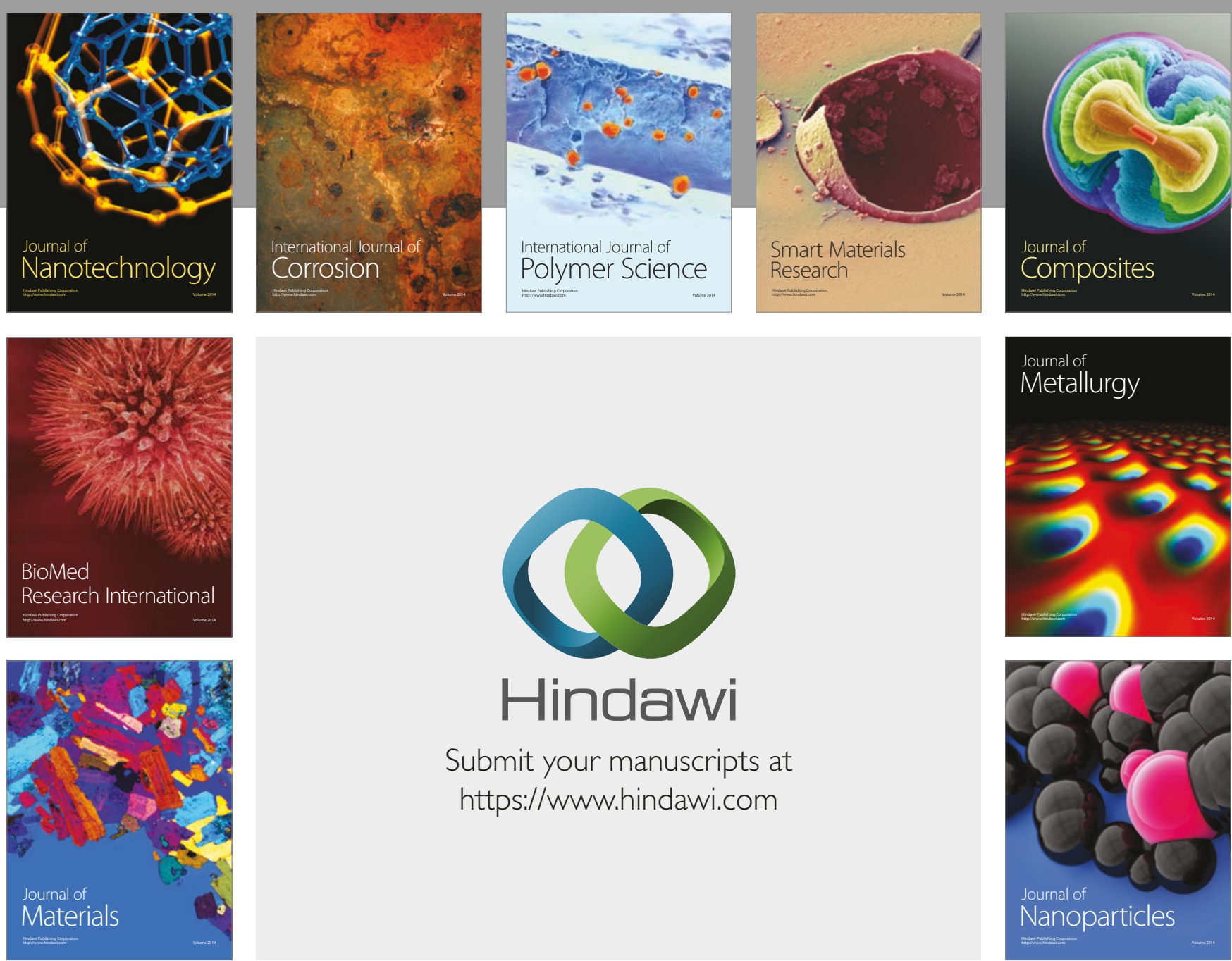

\section{Hindawi}

Submit your manuscripts at

https://www.hindawi.com
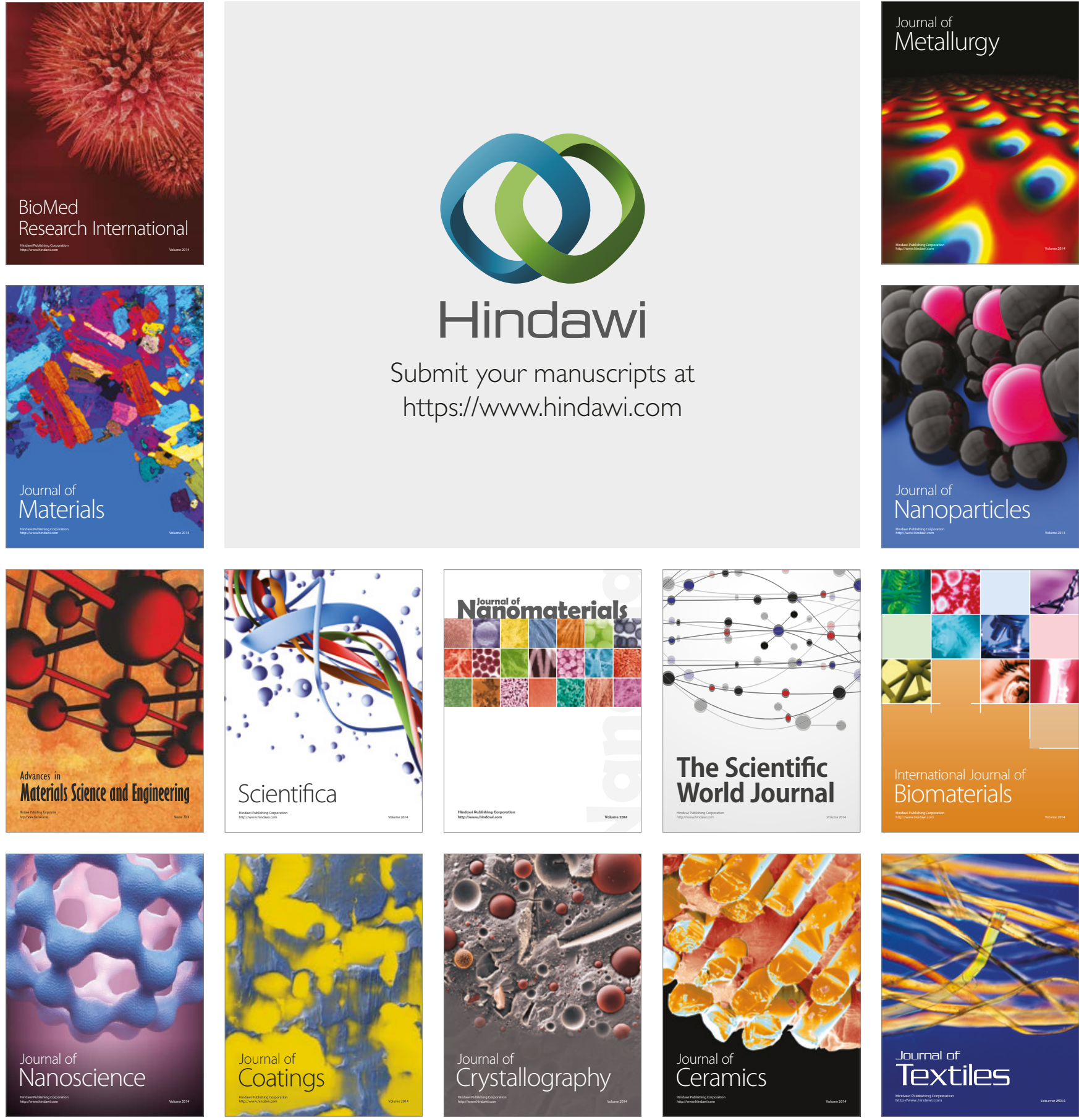

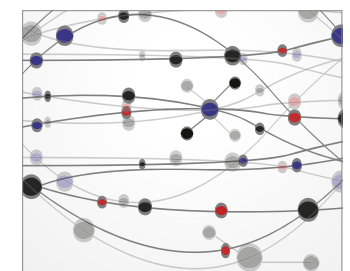

The Scientific World Journal
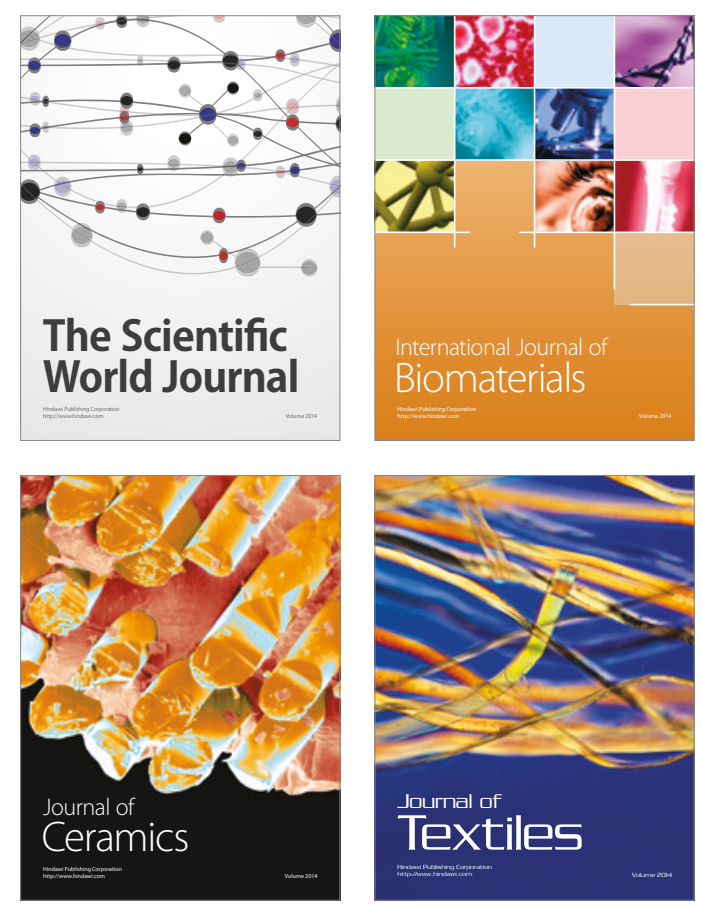